\title{
ALTERAÇÕES NA ESTRUTURA E NA DIVERSIDADE FLORÍSTICA NO PERÍODO 2002-2008 DE UMA FLORESTA OMBRÓFILA MISTA MONTANA DO CENTRO-SUL DO PARANÁ, BRASIL
}

\author{
Alex Roberto Sawczuk ${ }^{1}$, Afonso Figueiredo Filho ${ }^{2}$, Andrea Nogueira Dias ${ }^{3}$, \\ Luciano Farinha Watzlawick $^{4}$, Thiago Floriani Stepka ${ }^{5}$ \\ ${ }^{1}$ Eng. Florestal, M.Sc., Depto. de Extensão, IEF, Macapá, AP, Brasil - alex.sawczuk@ yahoo.com.br \\ ${ }^{2}$ Eng. Florestal, Dr., Depto. de Engenharia Florestal, UNICENTRO, Irati, PR, Brasil - afonso.figueiredo@ pq.cnpq.br \\ ${ }^{3}$ Eng $^{\mathrm{a}}$. Florestal, Dr ${ }^{\mathrm{a}}$., Depto. de Engenharia Florestal, UNICENTRO, Irati, PR, Brasil - andias@ irati.unicentro.br \\ ${ }^{4}$ Eng. Florestal, Dr., Depto. de Agronomia, UNICENTRO, Irati, PR, Brasil - luciano.watzlawick@pq.cnpq.br \\ ${ }^{5}$ Eng. Florestal, M.Sc., Doutorando em Eng. Florestal, UFPR, Curitiba, PR, Brasil - tfstepka@ yahoo.com.br
}

Recebido para publicação: 01/03/2011 - Aceito para publicação: 17/08/2011

\begin{abstract}
Resumo
As mudanças na estrutura sucessional e diversidade florística de um fragmento de Floresta Ombrófila Mista Montana, localizada na FLONA de Irati, Paraná, foram monitoradas ao longo de seis anos. Os dados foram coletados em 25 ha de parcelas permanentes, medidas em 2002, 2005 e 2008, em que todos os indivíduos arbóreos com DAP $\geq 10 \mathrm{~cm}$ foram medidos, numerados e identificados. Para o estudo da estrutura sucessional, os indivíduos foram classificados em 4 grupos ecofisiológicos: $a$ ) pioneiras; b) secundárias iniciais; c) secundárias tardias; e d) sem caracterização. Já a diversidade florística foi avaliada empregando-se os índices de Shannon $\left(H^{\prime}\right)$, Índice de Simpson ( $\left.D^{\prime}\right)$ e equabilidade de Pielou ( $\left.J^{\prime}\right)$. As análises demonstraram aumento de 89 para $90 \%$ no número de indivíduos pertencentes às espécies da categoria das secundárias, assim como o aumento de 4,46\% no número de espécies e de 3,80\% para gêneros, indicando que a floresta está cada vez mais diversificada (riqueza) e estruturada, sendo o estágio sucessional avançado o principal fator para o aparecimento de novas espécies e redução do número de indivíduos de espécies dominantes, conforme corroboram os valores dos índices de Shannon $\left(H^{\prime}=3,55\right.$ e 3,57), Simpson $\left(D^{\prime}=0,044 \mathrm{e}\right.$ $0,043)$ e equabilidade de Pielou $\left(J^{\prime}=75 \%\right)$ observados no período.
\end{abstract}

Palavras-chave: Floresta com araucária; sucessão florestal; índices de diversidade.

\begin{abstract}
Changes in structure and floristic diversity from 2002 to 2008 in Montane Mixed Rain Forest in central southern region of Paraná State, Brazil. The changes in the successional structure and floristic diversity of a fragment of Mixed Rain Forest, located on Irati National Forest, Parana State, were monitored over six years. Data were collected in an area of 25 ha, measured in 2002, 2005 and 2008 and on the three occasions, all trees with $\mathrm{DBH} \geq 10 \mathrm{~cm}$ were measured, numbered and identified. To study the successional structure the trees were classified into four ecophysiological groups: $a$ ) pioneer; $b$ ) early secondary; c) late secondary and d) no characterization. The floristic diversity was evaluated using the Shannon $\left(H^{\prime}\right)$, Simpson $\left(D^{\prime}\right)$ and Pielou's Evenness $\left(J^{\prime}\right)$ indices. The analyses showed increase from 89 to $90 \%$ in the number of individuals belonging to the category of secondary species, as well as an increase of $4.46 \%$ in the number of species and genera of $3.80 \%$, indicating that the forest is more diverse (richness) and structured. The main factor for this result is the advanced stage of succession which favor the emergence of new species and helps to reduce the number of individuals of dominant species as corroborated by the values of the indices of Shannon $\left(H^{\prime}=3.55\right.$ and 3.57), Simpson $\left(D^{`}=0.044\right.$ and 0.043$)$ and Pielou's Evenness $\left(\mathrm{J}^{\prime}=75 \%\right)$ during the period.

Keywords: Araucaria forest; forest succession; diversity indices.
\end{abstract}

\section{INTRODUÇÃO}

A Floresta Ombrófila Mista, caracterizada pela presença marcante da espécie Araucaria angustifolia, é uma das mais importantes formações florestais da região Sul do Brasil. Possuía 
originalmente área de $200.000 \mathrm{~km}^{2}$, ocorrendo no Paraná (40\% de sua superfície), Santa Catarina (31\%) e Rio Grande do Sul (25\%) e em manchas esparsas no sul de São Paulo (3\%), internando-se até o sul de Minas Gerais e Rio de Janeiro (1\%). Além disso, inclui-se uma pequena área na província de Misiones, na Argentina (BITTENCOURT et al., 2004) e Paraguai (SILVA et al., 2007).

A exuberância e terras férteis ocupadas pela Floresta Ombrófila Mista no interior do Paraná foram motivações para que colonizadores europeus e migrantes dos estados limítrofes de Santa Catarina e Rio Grande do Sul, nos séculos XIX e XX, promovessem intensa colonização. Esse processo foi baseado no extrativismo, com a floresta sendo derrubada e substituída, dando origem a cidades, com novos ciclos econômicos e culturais sendo implantados, tais como café, reflorestamentos e, mais recentemente, canade-açúcar e soja (SANQUETTA et al., 2001).

Obedecendo a esse tipo de ocupação rápido e desordenado da época, o qual foi favorecido pela falta de fiscalização efetiva e escasso estudo sobre a dinâmica dessa formação florestal, necessário ao manejo sustentável, pouco restou da Floresta Ombrófila Mista. Dos $40 \%$ dessa formação florestal que cobriam o estado do Paraná (CARVALHO, 2003), restaram, de acordo com um levantamento realizado pela Fundação de Pesquisas Florestais do Paraná (FUPEF) (CASTELLA; BRITEZ, 2004), 0,8\% dessa tipologia florestal em avançado estado de conservação e com alta biodiversidade, passíveis de estudos de acompanhamento fitoecológico.

Considerando a grande importância ambiental e econômico-social, o potencial e a complexidade que a Floresta Ombrófila Mista apresenta para a região Sul do país, são fundamentais o estudo e o conhecimento do comportamento de suas características estruturais ao longo do tempo.

De acordo com Shiver e Borders (1996), os métodos de inventários sucessivos que incluem unidades amostrais com árvores etiquetadas e numeradas permitem o monitoramento dos parâmetros crescimento, ingresso e mortalidade dos indivíduos e espécies, os quais, para Willians (2005), podem ser compreendidos e utilizados como descritores da estrutura de uma comunidade pela diversidade florística, a qual incorpora em um único índice a riqueza (número de espécies) e a abundância de cada espécie.

Assim, para Schneider (2002), o conhecimento e o comportamento da estrutura e diversidade florística e suas tendências ao longo do tempo permitem observar o bem-estar do sistema ecológico, os aspectos autoecológicos e sinecológicos das espécies, detectar o estádio sucessional e subsidiar planos de revegetação e manejo florestal sustentado.

Esta pesquisa teve como objetivo avaliar e documentar as mudanças ocorridas no período de 2002 a 2008 na estrutura e diversidade florística em um fragmento de Floresta Ombrófila Mista conservado por mais de 60 anos na Floresta Nacional (FLONA) de Irati, estado do Paraná.

Dessa forma, estabeleceram-se as seguintes hipóteses:

a) o estágio sucessional afeta a dinâmica da floresta;

b) em uma floresta em estágio sucessional avançado ocorre aumento na diversidade florística.

\section{MATERIAIS E MÉTODOS}

\section{Área de estudo}

A área de estudo se localiza na FLONA de Irati, situada no segundo planalto paranaense, na zona fisiográfica de Irati, paralelo $25^{\circ} 27^{\prime} 56^{\prime \prime}$ de latitude Sul com interseção com o meridiano $50^{\circ} 37^{\prime} 51^{\prime \prime}$ de longitude Oeste, a uma altitude média de 820 metros acima do nível do mar, apresentando relevo suave ondulado, no âmbito dos municípios de Fernandes Pinheiro e Teixeira Soares, estado do Paraná (MAZZA et al., 2005).

Segundo a classificação climática de Köppen, o clima de Irati é tipo Cfb - temperado, ou seja, Subtropical Úmido Mesotérmico, caracterizado por verões frescos, geadas severas e frequentes e sem estação seca (MAZZA et al., 2005). As médias mensais de precipitação pluviométrica e umidade relativa do ar são $193,97 \mathrm{~mm}$ e $79,58 \%$, respectivamente, com temperatura média máxima de $24,2^{\circ} \mathrm{C}$ e média mínima de $11{ }^{\circ} \mathrm{C}$ (FIGUEIREDO FILHO et al., 2006). Para Mazza et al. (2005) a Floresta Nacional de Irati apresenta um mosaico de formações geológicas do Paleozoico relacionadas aos grupos Depósitos Quaternários, Guatá e Passa Dois.

O Bioma Mata Atlântica ocupa $98 \%$ do estado do Paraná e a formação florestal que compõe a região da FLONA de Irati é a Floresta Ombrófila Mista Montana, tendo como principal espécie a Araucaria angustifolia (Bertol.) Kuntze associada com a Ocotea porosa (Nees) Barroso, formando 
agrupamentos característicos (INSTITUTO BRASILEIRO DE GEOGRAFIA E ESTATÍSTICA (IBGE), 1992; IBGE, 2010).

Nos anos de 2000-2002, num fragmento de Floresta Ombrófila Mista (1.272,9 ha), foram instaladas, pelo Departamento de Engenharia Florestal da UNICENTRO, 25 parcelas permanentes de 1 ha cada. Esse fragmento foi explorado de forma seletiva no passado, no entanto, há mais de 60 anos se encontra conservado e protegido, constituindo-se em um local sem similar para a pesquisa.

\title{
Coleta dos dados
}

Em 2002 foram instaladas e medidas 25 parcelas permanentes, com área de 1 ha (100 m x 100 m) cada uma, as quais foram remedidas em 2005 e 2008. Nessas ocasiões, todos os indivíduos arbóreos com diâmetros a 1,3 m (DAP) iguais ou acima de $10 \mathrm{~cm}$ foram medidos, numerados, identificados e posicionados em um sistema cartesiano $(\mathrm{X}, \mathrm{Y})$, constituindo-se na base de dados para a geração dos resultados da presente pesquisa. A identificação botânica seguiu o sistema de classificação Angiosperm Phylogeny Group II (APG II), que foi utilizado por Souza e Lorenzi (2005).

\begin{abstract}
Análise de dados
O estudo da estrutura sucessional implicou a identificação e classificação das espécies e seus indivíduos em grupos ecofisiológicos, tendo como base o trabalho realizado por Gandolfi et al. (1995), que separou as espécies em quatro categorias sucessionais: a) pioneiras - espécies de ciclo de vida curto completado sob condições de pleno sol para estabelecimento e reprodução; b) secundárias iniciais espécies que necessitam de plena luz para crescimento e reprodução; c) secundárias tardias consideradas aquelas espécies longevas, que crescem à sombra, mas exigem plena luz para reprodução; $d$ ) sem caracterização (indeterminadas) - em função da carência de informações, não puderam ser enquadradas nas classes anteriores.

As informações ecofisiológicas das espécies foram obtidas de trabalhos de Catharino et al. (2006), Mantovani et al. (2005), Isernhagen et al. (2001), Oliveira et al. (2001) e Fonseca e Rodrigues (2000).

Para a caracterização da diversidade florística e suas alterações no período estudado, foram empregados os índices de Shannon $\left(H^{\prime}\right)$, índice de Simpson ( $\left.D^{\prime}\right)$ e equabilidade de Pielou $\left(J^{\prime}\right)$, que, além de representarem a diversidade, permitem observar a uniformidade de distribuição dos indivíduos nas espécies da floresta. O suplemento FlorExel versão 3.1.2 (ARCE, 2007) foi utilizado para determinar os índices mencionados.
\end{abstract}

\section{RESULTADOS E DISCUSSÃO}

\section{Alterações na composição florística}

A composição florística presente nas três ocasiões em que a amostra foi medida está na tabela 1. No ano de 2002 existiam 14.518 árvores ( 25 ha) ou 580,72 indivíduos/ha, com 111 espécies identificadas de 76 gêneros, pertencentes a 44 famílias. Em 2005 ocorreram 14.300 indivíduos (572 indivíduos/ha) e não houve mudanças no número de espécies, gêneros e famílias. Finalmente, na medição de 2008, ocorreram 14.178 indivíduos (567 indivíduos/ha), divididos em 116 espécies identificadas e 79 gêneros pertencentes a 44 famílias.

Nas três ocasiões de medição, uma espécie foi identificada pelo táxon família (Rubiaceae), o que aumenta o número de espécies para 112 em 2002 e 2005 e para 117 em 2008 . Observou-se também a presença de 23 árvores em 2002, 10 em 2005 e uma árvore em 2008 que morreram antes de serem devidamente identificadas. Assim, no período de seis anos, a floresta teve mortalidade de 340 árvores, passando de 581 para 567 indivíduos/ha, e ingresso de 5 novas espécies (Figura 1).

A taxa de acréscimo de $0,74 \%$ /ano na riqueza de espécies, quando comparada a trabalhos realizados em áreas de mesma formação florestal, está bastante próxima ao valor encontrado por Moscovich (2006), que foi de $0,93 \% / a n o$, e um tanto acima de valores citados por outros autores, como Barth Filho (2002), que não constatou aumento de riqueza no período estudado, Schaaf (2001) e Pizzato (1999), que encontraram taxas de aumento de riqueza de 0,39 e 0,51\%/ano, respectivamente.

$\mathrm{O}$ acréscimo líquido de cinco espécies no período é devido ao ingresso de sete novas espécies no ano de 2008, sendo $43 \%$ delas secundárias iniciais e $43 \%$ secundárias tardias. Nesse mesmo ano desapareceram duas espécies, uma secundária tardia e outra pioneira. 
Tabela 1. Composição florística e estrutura sucessional para o fragmento de Floresta Ombrófila Mista Montana da Floresta Nacional de Irati, estado do Paraná, para os anos de 2002, 2005 e 2008.

Table 1. Floristic composition and successional structure of the fragment of Montane Mixed Rain Forest in Irati National Forest, Paraná State, for the years 2002, 2005 and 2008.

\begin{tabular}{|c|c|c|c|c|c|c|c|c|c|}
\hline \multirow{2}{*}{ Família } & \multirow{2}{*}{ Nome científico } & \multicolumn{3}{|c|}{ Número de indivíduos } & \multirow{2}{*}{$\begin{array}{r}\text { Dinâmica } \\
(2002- \\
2008) \\
\end{array}$} & \multicolumn{4}{|c|}{$\begin{array}{l}\text { Grupos } \\
\text { ecofisiológicos }\end{array}$} \\
\hline & & 2002 & 2005 & 2008 & & $\mathbf{p}$ & $\mathbf{S i}$ & st & $\mathbf{i}$ \\
\hline Anacardiaceae & Lithraea molleoides (Vell.) Engl. & 31 & 28 & 22 & -9 & & $\mathrm{x}$ & & \\
\hline \multirow[t]{2}{*}{ Annonaceae } & Rollinia sylvatica (A.St.-Hil.) Martius & 2 & 2 & 3 & 1 & & $\mathrm{x}$ & & \\
\hline & Rollinia rugulosa Schltdl. & 1 & 1 & 1 & 0 & $\mathrm{X}$ & & & \\
\hline \multirow[t]{4}{*}{ Aquifoliaceae } & Ilex theezans Mart. ex Reissek & 319 & 304 & 286 & -33 & & $\mathrm{x}$ & & \\
\hline & Ilex dumosa Reissek & 40 & 33 & 32 & -8 & & $\mathrm{x}$ & & \\
\hline & Ilex paraguariensis A. St.-Hil. & 1506 & 1400 & 1334 & -172 & & & $\mathrm{x}$ & \\
\hline & Ilex brevicuspis Reissek & 9 & 10 & 10 & 1 & & $\mathrm{x}$ & & \\
\hline Araliaceae & $\begin{array}{l}\text { Schefflera morototoni (Aubl.) Maguire, } \\
\text { Steyerm. \& Frodin }\end{array}$ & 31 & 28 & 24 & -7 & & $\mathrm{x}$ & & \\
\hline Araucariaceae & Araucaria angustifolia (Bertol.) Kuntze & 1053 & 1054 & 1058 & 5 & & & $\mathrm{x}$ & \\
\hline Arecaceae & Syagrus romanzoffiana (Cham.) Glassman & 450 & 453 & 446 & -4 & & $\mathrm{x}$ & & \\
\hline \multirow[t]{5}{*}{ Asteraceae } & Gochnatia polymorpha (Less.) Cabrera & 1 & 1 & 0 & -1 & $\mathrm{x}$ & & & \\
\hline & Vernonanthura petiolaris (DC.) H. Rob. & 108 & 82 & 61 & -47 & $\mathrm{x}$ & & & \\
\hline & Piptocarpha angustifolia Dusén ex Malme & 56 & 45 & 41 & -15 & $\mathrm{x}$ & & & \\
\hline & Piptocarpha tomentosa Baker & 15 & 17 & 16 & 1 & $\mathrm{x}$ & & & \\
\hline & Vernonanthura discolor (Spreng.) H. Rob. & 52 & 52 & 48 & -4 & $\mathrm{x}$ & & & \\
\hline Bignoniaceae & Jacaranda micrantha Cham. & 77 & 81 & 80 & 3 & & $\mathrm{x}$ & & \\
\hline Canellaceae & Capsicodendron dinisii (Schwacke) Occhioni & 362 & 337 & 317 & -45 & $\mathrm{x}$ & & & \\
\hline Cardiopteridaceae & Citronella paniculata (Mart.) R.A. Howard & 1 & 1 & 0 & -1 & & & $\mathrm{X}$ & \\
\hline \multirow[t]{2}{*}{ Celastraceae } & Maytenus grandiflorus Reissek & 1 & 1 & 4 & 3 & & & $\mathrm{x}$ & \\
\hline & Maytenus muelleri Schwacke & 6 & 7 & 6 & 0 & & & $\mathrm{X}$ & \\
\hline Clethraceae & Clethra scabra Pers. & 133 & 122 & 108 & -25 & $\mathrm{x}$ & & & \\
\hline \multirow[t]{2}{*}{ Cunoniaceae } & Weinmannia paulliniifolia Pohl ex Ser. & 0 & 0 & 1 & 1 & & $\mathrm{x}$ & & \\
\hline & Lamanonia ternata Vell. & 4 & 4 & 4 & 0 & & $\mathrm{x}$ & & \\
\hline Elaeocarpaceae & Sloanea monosperma Vell. & 124 & 116 & 110 & -14 & & & $\mathrm{x}$ & \\
\hline Erythroxylaceae & Erythroxylum deciduum A. St.-Hil. & 1 & 1 & 1 & 0 & $\mathrm{X}$ & & & \\
\hline \multirow[t]{3}{*}{ Euphorbiaceae } & $\begin{array}{l}\text { Sebastiania commersoniana (Baill.) L.B.Sm. } \\
\text { \& Downs }\end{array}$ & 5 & 6 & 7 & 2 & & $\mathrm{x}$ & & \\
\hline & Gymnanthes concolor Spreng. & 1 & 2 & 2 & 1 & & & & $\mathrm{x}$ \\
\hline & Sapium glandulosum (L.) Morong & 28 & 30 & 28 & 0 & $\mathrm{x}$ & & & \\
\hline \multirow[t]{2}{*}{ Fabaceae - Caes } & Cassia leptophylla Vogel & 19 & 19 & 19 & 0 & & $\mathrm{x}$ & & \\
\hline & Ormosia arborea (Vell.) Harms & 2 & 3 & 2 & 0 & & $\mathrm{x}$ & & \\
\hline \multirow[t]{3}{*}{ Fabaceae - Fabo } & Dalbergia frutescens (Vell.) Britton & 244 & 244 & 236 & -8 & & $\mathrm{x}$ & & \\
\hline & Machaerium stipitatum (DC.) Vogel & 88 & 70 & 70 & -18 & & $\mathrm{X}$ & & \\
\hline & Lonchocarpus sp. & 0 & 0 & 1 & 1 & & $\mathrm{x}$ & & \\
\hline \multirow[t]{4}{*}{ Fabaceae - Mimo } & Mimosa scabrella Benth. & 27 & 14 & 11 & -16 & $\mathrm{x}$ & & & \\
\hline & $\begin{array}{l}\text { Albizia edwallii (Hoehne) Barneby \& J. } \\
\text { Grimes }\end{array}$ & 7 & 7 & 7 & 0 & & $\mathrm{x}$ & & \\
\hline & Inga virescens Benth. & 39 & 39 & 41 & 2 & & & & $\mathrm{X}$ \\
\hline & Parapiptadenia rigida (Benth.) Brenan & 26 & 28 & 30 & 4 & & $\mathrm{x}$ & & \\
\hline \multirow[t]{2}{*}{ Lamiaceae } & Aegiphila sellowiana Cham. & 6 & 6 & 6 & 0 & $\mathrm{x}$ & & & \\
\hline & Vitex megapotamica (Spreng.) Moldenke & 2 & 2 & 2 & 0 & & $\mathrm{x}$ & & \\
\hline \multirow[t]{5}{*}{ Lauraceae } & Cinnamomum vesiculosum (Nees) Kosterm. & 10 & 9 & 9 & -1 & & $\mathrm{X}$ & & \\
\hline & Nectandra grandiflora Nees & 940 & 919 & 885 & -55 & & & $\mathrm{x}$ & \\
\hline & $\begin{array}{l}\text { Cinnamomum sellowianum (Nees \& C. Mart. } \\
\text { ex Nees) Kosterm. }\end{array}$ & 62 & 59 & 57 & -5 & & & & $\mathrm{X}$ \\
\hline & Cryptocarya aschersoniana $\mathrm{Mez}$ & 6 & 7 & 7 & 1 & & & $\mathrm{x}$ & \\
\hline & Ocotea puberula (Rich.) Nees & 353 & 339 & 329 & -24 & & & $\mathrm{x}$ & \\
\hline
\end{tabular}




\begin{tabular}{|c|c|c|c|c|c|c|c|c|c|}
\hline & Nectandra megapotamica (Spreng.) Mez & 429 & 435 & 443 & 14 & & & $\mathrm{x}$ & \\
\hline & Cinnamomum glaziovii (Mez) Kosterm. & 2 & 2 & 2 & 0 & & & $\mathrm{x}$ & \\
\hline & Ocotea diospyrifolia (Meisn.) Mez & 227 & 225 & 222 & -5 & & & $\mathrm{x}$ & \\
\hline & Ocotea corymbosa (Meisn.) Mez & 36 & 39 & 52 & 16 & & & $\mathrm{X}$ & \\
\hline & Ocotea indecora (Schott) Mez & 16 & 16 & 16 & 0 & & & $\mathrm{x}$ & \\
\hline & Ocotea porosa (Nees) Barroso & 484 & 479 & 480 & -4 & & & $\mathrm{x}$ & \\
\hline & Persea willdenowii Kosterm. & 20 & 19 & 19 & -1 & & & $\mathrm{x}$ & \\
\hline & Ocotea odorifera (Vell.) Rohwer & 1298 & 1310 & 1315 & 17 & & & $\mathrm{x}$ & \\
\hline Loganiaceae & Strychnos brasiliensis (Spreng.) Mart. & 1 & 2 & 2 & 1 & $\mathrm{x}$ & & & \\
\hline Lythraceae & Lafoensia vandelliana Cham. \& Schltdl. & 24 & 23 & 22 & -2 & & $\mathrm{x}$ & & \\
\hline Malvaceae & Luehea divaricata Mart. \& Zucc. & 19 & 16 & 15 & -4 & & $\mathrm{x}$ & & \\
\hline \multirow[t]{3}{*}{ Meliaceae } & Cabralea canjerana (Vell.) Mart. & 14 & 14 & 14 & 0 & & & $\mathrm{x}$ & \\
\hline & Trichilia claussenii C.DC. & 1 & 1 & 1 & 0 & & & $\mathrm{x}$ & \\
\hline & Cedrela fissilis Vell. & 386 & 379 & 378 & -8 & & $\mathrm{x}$ & & \\
\hline Monimiaceae & Mollinedia elegans Tul. & 0 & 0 & 1 & 1 & & & $\mathrm{X}$ & \\
\hline \multirow[t]{2}{*}{ Moraceae } & Ficus enormis (Mart. ex Miq.) Miq. & 3 & 3 & 2 & -1 & & & $\mathrm{x}$ & \\
\hline & Ficus dendrocida Kunth & 1 & 1 & 1 & 0 & & & & $\mathrm{x}$ \\
\hline \multirow[t]{3}{*}{ Myrsinaceae } & Myrsine laetevirens (Mez) Arechav & 7 & 8 & 9 & 2 & $\mathrm{x}$ & & & \\
\hline & Myrsine umbellata Mart. & 582 & 544 & 486 & -96 & & $\mathrm{x}$ & & \\
\hline & Myrsine coriacea (Sw.) R. Br. & 1 & 3 & 4 & 3 & $\mathrm{x}$ & & & \\
\hline \multirow[t]{17}{*}{ Myrtaceae } & Psidium sp. & 27 & 30 & 30 & 3 & & $\mathrm{x}$ & & \\
\hline & Myrcia hebepetala DC. & 238 & 252 & 284 & 46 & & & & $\mathrm{x}$ \\
\hline & $\begin{array}{l}\text { Myrceugenia miersiana (Gardner) D. Legrand } \\
\text { \& Kausel }\end{array}$ & 1 & 1 & 1 & 0 & & & & $\mathrm{x}$ \\
\hline & $\begin{array}{l}\text { Myrciaria floribunda (West ex Willd.) O. } \\
\text { Berg }\end{array}$ & 157 & 194 & 224 & 67 & & & $\mathrm{x}$ & \\
\hline & $\begin{array}{l}\text { Campomanesia guazumifolia (Cambess.) O. } \\
\text { Berg }\end{array}$ & 1 & 1 & 1 & 0 & & $\mathrm{x}$ & & \\
\hline & Eugenia involucrata DC. & 154 & 171 & 206 & 52 & & & $\mathrm{x}$ & \\
\hline & Campomanesia xanthocarpa O. Berg & 152 & 158 & 162 & 10 & & & $\mathrm{x}$ & \\
\hline & Eugenia pluriflora DC. & 5 & 5 & 4 & -1 & & & $\mathrm{x}$ & \\
\hline & Myrcia lajeana D. Legrand & 2 & 5 & 10 & 8 & & $\mathrm{x}$ & & \\
\hline & Myrcia rostrata DC. & 220 & 217 & 218 & -2 & $\mathrm{x}$ & & & \\
\hline & Myrcia guianensis (Aubl.) DC. & 2 & 4 & 5 & 3 & & & & $\mathrm{x}$ \\
\hline & Plinia trunciflora (O. Berg) Kausel & 37 & 37 & 37 & 0 & & & $\mathrm{x}$ & \\
\hline & Blepharocalyx salicifolius (Kunth) O. Berg. & 0 & 0 & 1 & 1 & & & $\mathrm{x}$ & \\
\hline & Mosiera prismatica (D. Legrand) Landrum & 112 & 120 & 122 & 10 & & & & $\mathrm{x}$ \\
\hline & Gomidesia affinis (Cambess.) O. Berg & 0 & 0 & 1 & 1 & & $\mathrm{x}$ & & \\
\hline & Eugenia uniflora $\mathrm{L}$. & 9 & 7 & 6 & -3 & & & $\mathrm{x}$ & \\
\hline & Eugenia pyriformis Cambess. & 1 & 1 & 1 & 0 & & & $\mathrm{x}$ & \\
\hline Picramniaceae & Picramnia parvifolia Engl. & 5 & 6 & 6 & 1 & & $\mathrm{x}$ & & \\
\hline Polygonaceae & Ruprechtia laxiflora Meisn. & 1 & 1 & 1 & 0 & & & $\mathrm{x}$ & \\
\hline Proteaceae & Roupala brasiliensis Klotzsch & 25 & 21 & 20 & -5 & & & $\mathrm{x}$ & \\
\hline Quillajaceae & Quillaja brasiliensis (A.St.-Hil \& Tul.) Mart. & 6 & 7 & 7 & 1 & $\mathrm{x}$ & & & \\
\hline Rosaceae & $\begin{array}{l}\text { Prunus brasiliensis (Cham. \& Schltdl.) D. } \\
\text { Dietr. }\end{array}$ & 331 & 299 & 273 & -58 & & $\mathrm{x}$ & & \\
\hline \multirow[t]{5}{*}{ Rubiaceae } & Coussarea contracta (Walp.) Müll.Arg. & 498 & 556 & 626 & 128 & & & $\mathrm{x}$ & \\
\hline & Psychotria vellosiana Benth. & 132 & 128 & 135 & 3 & & & $\mathrm{x}$ & \\
\hline & Randia ferox (Cham \& Schltdl.) DC. & 2 & 2 & 2 & 0 & $\mathrm{x}$ & & & \\
\hline & Rubiaceae (N.I) & 2 & 2 & 2 & 0 & & & & $\mathrm{x}$ \\
\hline & Rudgea jasminoides (Cham.) Müll.Arg. & 3 & 7 & 7 & 4 & & & $\mathrm{x}$ & \\
\hline \multirow[t]{3}{*}{ Rutaceae } & $\begin{array}{l}\text { Zanthoxylum kleinii (R.S. Cowan) P.G. } \\
\text { Waterman }\end{array}$ & 10 & 11 & 11 & 1 & & $\mathrm{x}$ & & \\
\hline & Citrus sp. & 2 & 3 & 3 & 1 & $\mathrm{x}$ & & & \\
\hline & Zanthoxylum rhoifolium Lam. & 34 & 33 & 30 & -4 & & $\mathrm{x}$ & & \\
\hline
\end{tabular}




\begin{tabular}{|c|c|c|c|c|c|c|c|c|c|}
\hline \multirow[t]{8}{*}{ Salicaceae } & Banara tomentosa $\mathrm{Clos}$ & 6 & 6 & 6 & 0 & & & $\mathrm{x}$ & \\
\hline & Casearia decandra Jacq. & 901 & 857 & 840 & -61 & & $\mathrm{x}$ & & \\
\hline & Casearia lasiophylla Eichler & 23 & 31 & 44 & 21 & & $\mathrm{x}$ & & \\
\hline & Casearia gossypiosperma Briq. & 1 & 1 & 1 & 0 & & $\mathrm{x}$ & & \\
\hline & Casearia sp. & 10 & 14 & 9 & -1 & & & $\mathrm{x}$ & \\
\hline & Casearia sylvestris $\mathrm{Sw}$. & 307 & 329 & 356 & 49 & & $\mathrm{x}$ & & \\
\hline & Casearia obliqua Spreng. & 119 & 125 & 124 & 5 & & $\mathrm{x}$ & & \\
\hline & Xylosma pseudosalzmanii Sleumer & 18 & 19 & 20 & 2 & & $\mathrm{x}$ & & \\
\hline \multirow[t]{5}{*}{ Sapindaceae } & Cupania vernalis Cambess. & 46 & 46 & 49 & 3 & & $\mathrm{x}$ & & \\
\hline & Diatenopteryx sorbifolia Radlk. & 40 & 45 & 54 & 14 & & & $\mathrm{x}$ & \\
\hline & Matayba elaeagnoides Radlk. & 455 & 428 & 395 & -60 & & $\mathrm{x}$ & & \\
\hline & $\begin{array}{l}\text { Allophylus edulis (A. St.-Hil., Cambess. \& A. } \\
\text { Juss.) Radlk. }\end{array}$ & 123 & 145 & 157 & 34 & & $\mathrm{x}$ & & \\
\hline & Allophylus petiolulatus Radlk. & 24 & 27 & 25 & 1 & & $\mathrm{x}$ & & \\
\hline \multirow[t]{2}{*}{ Sapotaceae } & $\begin{array}{l}\text { Chrysophyllum gonocarpum (Mart. \& } \\
\text { Eichler) Engl. }\end{array}$ & 89 & 98 & 98 & 9 & & & $\mathrm{x}$ & \\
\hline & $\begin{array}{l}\text { Chrysophyllum marginatum (Hook. et Arn.) } \\
\text { Radlk. }\end{array}$ & 28 & 31 & 32 & 4 & & & $\mathrm{x}$ & \\
\hline Simaroubaceae & Picrasma crenata (Vell.) Engl. & 55 & 55 & 60 & 5 & & & & $\mathrm{x}$ \\
\hline \multirow[t]{3}{*}{ Solanaceae } & Solanum sanctaecatharinae Dunal & 9 & 11 & 9 & 0 & $\mathrm{x}$ & & & \\
\hline & Solanum bullatum Vell. & 1 & 1 & 1 & 0 & $\mathrm{x}$ & & & \\
\hline & Solanum pseudoquina A.St.-Hil. & 0 & 0 & 3 & 3 & $\mathrm{x}$ & & & \\
\hline Styracaceae & Styrax leprosus Hook. \& Arn. & 160 & 139 & 117 & -43 & & & $\mathrm{x}$ & \\
\hline \multirow[t]{3}{*}{ Symplocaceae } & Symplocos tenuifolia Brand & 1 & 1 & 1 & 0 & & & & $\mathrm{x}$ \\
\hline & Symplocos uniflora (Pohl) Benth. & 0 & 0 & 1 & 1 & & & $\mathrm{x}$ & \\
\hline & Symplocos tetrandra (Mart.) Miq. & 2 & 2 & 2 & 0 & & & $\mathrm{x}$ & \\
\hline Theaceae & Laplacea fruticosa (Schrad.) Kuboski & 45 & 34 & 31 & -14 & & & $\mathrm{x}$ & \\
\hline Winteraceae & Drimys brasiliensis Miers & 64 & 64 & 60 & -4 & & $\mathrm{x}$ & & \\
\hline N.I. Morta & N.I. Morta & 23 & 10 & 1 & -22 & & & & \\
\hline 45 & 81 & 14518 & 14300 & 14178 & -340 & 22 & 43 & 43 & 11 \\
\hline
\end{tabular}

Nota: p: pioneira; si: secundária inicial; st: secundária tardia; e i: indeterminada.

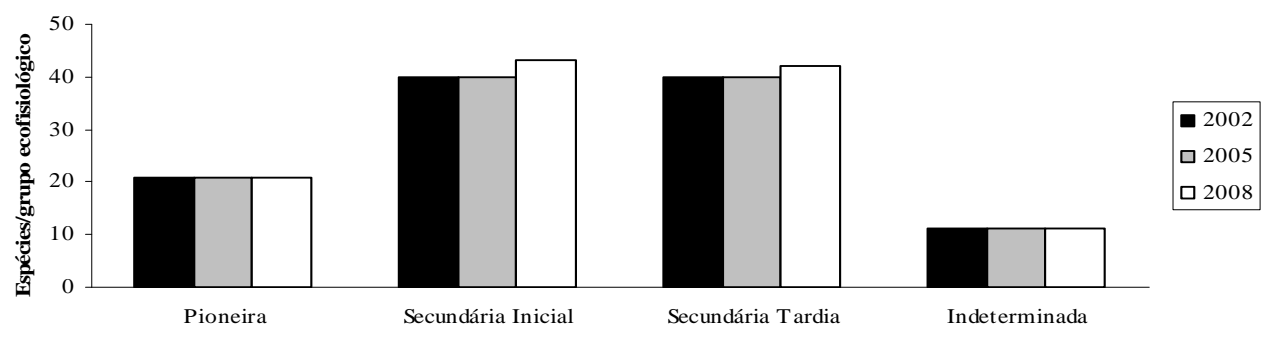

Figura 1. Alteração no número de espécies por grupo ecofisiológico no fragmento de Floresta Ombrófila Mista Montana da FLONA de Irati, estado do Paraná, entre os anos de 2002 e 2008.

Figure 1. Changes in the number of species by ecophysiological group in the fragment of Montane Mixed Rain Forest in Irati National Forest, Paraná State, from 2002 to 2008.

A mortalidade de 2,34\% no período ocorreu principalmente nas espécies Ilex paraguariensis, com redução de 6,8 ind./ha (18,8\%), e Casearia decandra, com 2,4 ind./ha (6,6\%). Essa redução ocorrida no número de indivíduos da comunidade é bastante próxima ao valor encontrado por Moscovich (2006), que encontrou mortalidade de $2,86 \%$ em um período de 8 anos. Segundo ele, a floresta se encontrava em estádio sucessional de médio a avançado.

As espécies pertencentes ao grupo ecofisiológico das pioneiras foram as que mais perderam indivíduos em porcentagem (14\%) no período, passando de 41,6 para 35,8 indivíduos/ha. Essas árvores eram de pequenos diâmetros e morreram devido à competição por espaço, nutrientes, luz e água com indivíduos de outras espécies, como Araucaria angustifolia, Ocotea porosa e Ocotea odorifera (Figura 2). 
Já o maior aumento em porcentagem $(11,7 \%)$ no número de indivíduos foi nas espécies indeterminadas, que passou de 20,6 para 23 indivíduos/ha. Essa carência de identificação pode ser resultado da ocorrência de espécies que ocupam lugares em estágio bastante avançado de sucessão ecológica e, assim, não foram catalogadas em nenhum outro estudo dessa mesma tipologia florestal. Já o número de indivíduos das espécies secundárias iniciais e tardias apresentaram percentuais de $-5 \%$ e $0,1 \%$, respectivamente.

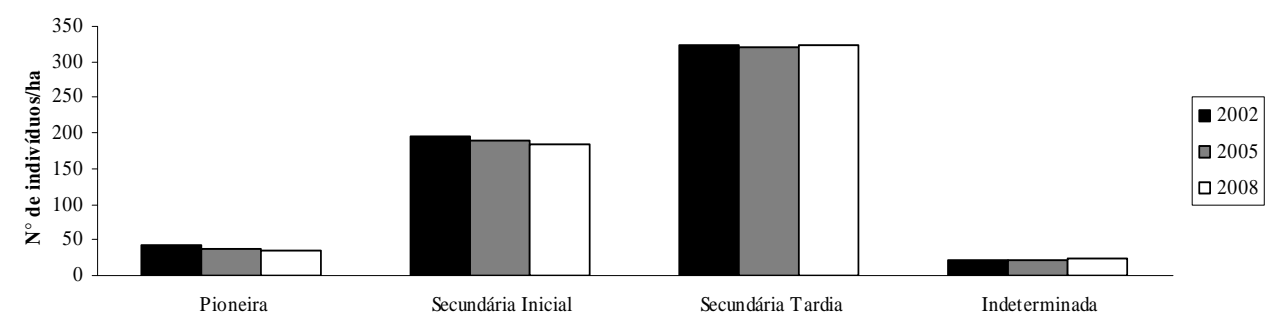

Figura 2. Alteração no número de indivíduos/ha nos grupos ecofisiológicos no fragmento de Floresta Ombrófila Mista Montana da Floresta Nacional de Irati, estado do Paraná, entre os anos de 2002 e 2008

Figure 2. Changes in the number of individuals/ha in the ecophysiological groups in the fragment of Montane Mixed Rain Forest in Irati National Forest, Paraná State, from 2002 to 2008.

As informações ecofisiológicas de espécies e indivíduos deste trabalho estão de acordo com Lamprecht (1990), que relatou que tanto a mortalidade de indivíduos quanto o aumento da riqueza de espécies ocorrido nas comunidades podem ser explicados pelo estádio sucessional. Para ele, as florestas maduras são extremamente diversificadas, com $14 \%$ do total de espécies e indivíduos de heliófitas (pioneiras) e $86 \%$ de esciófitas (secundárias). Nas florestas maduras, as mudanças são influenciadas pelas clareiras, provocadas por raios, tombamento, envelhecimento, ataque de fungos e insetos, e que são fundamentais para estrutura e composição variadas. Esse mesmo autor afirmou ainda que a regeneração de indivíduos de espécies heliófitas é quase inexistente, devido às condições desfavoráveis de sombra criada pelos estratos superiores bem definidos.

\section{Alterações na diversidade florística}

Os valores dos índices de diversidade florística por ano de medição e os valores percentuais de variação no intervalo de tempo estão apresentados na tabela 2.

De acordo com os índices de Shannon $\left(H^{\prime}\right)$, Simpson ( $\left.D^{\prime}\right)$ e equabilidade de Pielou $\left(J^{\prime}\right)$, apresentados na tabela 2, a área ( 25 ha) estudada apresentou altos valores de diversidade florística nas medições de 2002, 2005 e 2008, com valores de $H^{\prime}$ 'superiores a alguns índices estimados por outros autores, como Jarenkow (1997), que obteve $H^{\prime}=2,93$ e $J^{\prime}=0,805$; Durigan (1999), com $H^{\prime}=3,51 ; D^{\prime}=0,049$ e $J^{\prime}$ = 0,829; Schaaf (2001), com $D^{\prime}=0,21$ e 0,26; e Watzlawick et al. (2005), que encontraram $H^{\prime}=3,26$ e $D^{\prime}=$ 0,04 . Todos esses autores também realizaram trabalhos em Floresta Ombrófila Mista.

Tabela 2. Índices de diversidade para o fragmento de Floresta Ombrófila Mista Montana na Floresta Nacional de Irati, estado do Paraná, nos anos de 2002, 2005 e 2008.

Table 2. Diversity indices for the fragment of Montane Mixed Rain Forest in Irati National Forest, Parana State, for the years 2002, 2005 and 2008.

\begin{tabular}{lccccccc}
\hline \multirow{2}{*}{ Índices de diversidade } & \multicolumn{3}{c}{ Ano de medição } & \multicolumn{4}{c}{ Variação no tempo (\%) } \\
\cline { 2 - 8 } & $\mathbf{2 0 0 2}$ & $\mathbf{2 0 0 5}$ & $\mathbf{2 0 0 8}$ & $\mathbf{2 0 0 2 / 2 0 0 5}$ & $\mathbf{2 0 0 5 / 2 0 0 8}$ & $\mathbf{2 0 0 2 / 2 0 0 8}$ & Ano \\
\hline Número de indivíduos amostrados & 14518 & 14300 & 14178 & $-1,50$ & $-0,85$ & $-2,34$ & $-0,39$ \\
Número de espécies & 112 & 112 & 117 & 0,00 & 4,46 & 4,46 & 0,74 \\
Índice de Shannon $\left(H^{\prime}\right)$ & 3,55 & 3,56 & 3,57 & 0,28 & 0,28 & 0,56 & 0,09 \\
Índice de Simpson $\left(D^{\prime}\right)$ & 0,044 & 0,044 & 0,043 & 0,00 & $-2,27$ & $-2,27$ & $-0,38$ \\
Îndice de equabilidade de Pielou $\left(J^{\prime}\right)$ & 0,75 & 0,76 & 0,75 & 1,33 & $-1,32$ & 0,00 & 0,00 \\
\hline
\end{tabular}


Pode ser observado na tabela 2 que houve variações em todos os índices ao longo de todas as ocasiões de medição. Porém, em uma análise mais criteriosa com o índice de Shannon $\left(H^{\prime}\right)$, verifica-se que a diversidade da floresta estudada aumentou $(0,56 \%)$ no período de estudo, devido ao ingresso de 5 novas espécies e a mortalidade de 340 indivíduos, ocorrida principalmente nas espécies mais densas, como, por exemplo, Ilex paraguariensis, Myrsine umbellata, Casearia decandra e Prunus brasiliensis. Esse fato é corroborado pelo índice de Simpson, o qual apresentou uma queda $(2,27 \%)$ na dominância das espécies e consequente diminuição na probabilidade, que era de $4,4 \%$, de que dois indivíduos sorteados aleatoriamente na floresta pertençam à mesma espécie, para $4,3 \%$, ou seja, uma redução de $0,38 \% /$ ano, evidenciando que o estágio sucessional avançado da floresta favorece o ingresso de novas espécies e uniformidade de distribuição de indivíduos dentro das espécies.

Ressalte-se que, na última medição (2008), estava acontecendo a morte de taquaras, as quais ocorrem em reboleiras e ocupavam grandes áreas, e, simultaneamente, observou-se alta regeneração de indivíduos arbóreos, o que poderá acarretar alterações mais importantes na riqueza da floresta.

Segundo Mantovani et al. (2005), em áreas de vegetação na fase menos avançada, os índices de diversidade e equabilidade foram aproximadamente $10 \%$ inferiores aos das unidades amostrais localizadas em áreas com vegetação mais avançada, porém os valores de diversidade devem ser tomados apenas como estimativas, pois o uso de metodologias de inventário diferenciadas, tamanho amostral e outras variáveis interferem diretamente sobre o valor desses índices. A inclusão ou exclusão de alguma espécie de alta densidade, ou diâmetro-limite, também pode provocar alterações significativas no valor desses índices.

\section{CONCLUSÕES}

As mudanças ocorridas na floresta após 60 anos de conservação e seis anos de monitoramento permitem concluir que:

- A dinâmica foi bastante influenciada pelo avançado estágio de sucessão em que se encontra a floresta, apresentando tendência de aumento de espécies e indivíduos arbóreos (DAP $\geq 10 \mathrm{~cm}$ ) do grupo ecofisiológico das secundárias, porém uma diminuição do número de plantas na área estudada, devido à competição inter e intraespecífica e senilidade.

- O baixo ingresso de espécies pioneiras sugere a formação de um povoamento composto, na sua grande maioria, por espécies secundárias iniciais e tardias. Isso permite inferir que a floresta possui estrutura estável (com estratos bem definidos), sendo esta controlada pela luminosidade.

- As condições naturais de desenvolvimento da floresta indicam uma tendência de aumento da diversidade. Isso se deve ao aumento no número de espécies secundárias beneficiadas pela luminosidade e mortalidade de indivíduos nas espécies mais densas, como observado nos índices de Shannon e Simpson.

- As espécies Ilex paraguariensis, Ocotea odorifera, Araucaria angustifolia, Nectandra grandiflora e Casearia decandra caracterizam a fitofisionomia da floresta, a qual se demonstra totalmente recuperada, em condições naturais de desenvolvimento e sem evidências de ações antrópicas realizadas no passado, bastante diversificada e estruturada, porém com a grande maioria de seus indivíduos pertencentes a poucas espécies de poucas famílias botânicas, o que parece ser uma característica dessa formação florestal, conforme observado em outros trabalhos de mesmo conteúdo.

\section{RECOMENDAÇÕES}

São necessários estudos de longa duração e específicos sobre ingresso, mortalidade e corte a fim de se conhecer o comportamento dessa tipologia florestal com intervenção objetivando a definição de estratégias de manejo e conservação.

\section{REFERÊNCIAS}

ARCE, J. E. FlorExel. versão 3.2.1. Suplemento para Microsoft Excel®. Curitiba, 2007.

BARTH FILHO, N. Monitoramento do crescimento e da produção em Floresta Ombrófila Mista com uso de parcelas permanentes. 86 f. Dissertação (Mestrado em Manejo Florestal) - Universidade Federal do Paraná, Curitiba, 2002. 
BITTENCOURT, J. V. M.; HIGA, A. R.; MAZZA, M. C.; RUAS, P. M.; RUAS, C. F.; CACCAVARI, M.; FASSOLA, H. Conservation, management and sustainable use of Araucaria angustifolia genetic resources in Brazil. In: VINCENTI, B.; W. AMARAL, N.; MEILLEUR, B. (Eds), Challenges in managing forest genetic resources for livelihoods. Examples from Argentina and Brazil. Rome, Italy: International Plant Genetic Resources Institute, 2004. p. 133 - 148.

CARVALHO, P. E. R. Espécies florestais brasileiras. Brasília: Embrapa Florestas, 2003. 1039 p.

CASTELlA, P. R.; BRITEZ, R. M. A floresta com araucária no Paraná: conservação e diagnóstico dos remanescentes florestais. Brasília: Ministério do Meio Ambiente, Fundação de Pesquisas Florestais do Paraná, 2004. 236 p.

CATHARINO, E. L. M.; BERNACCI, L. C.; FRANCO, G.. A. D. C.; DURIGAN, G.; METZGER, J. P. Aspectos da composição e diversidade do componente arbóreo das florestas da Reserva Florestal do Morro Grande, Cotia, SP. Biota Neotrop. v. 6 n. 2, May/Aug 2006 <http://www.biotaneotropica.org.br/ v6n2/pt/abstract?article+bn00306022006>. Acesso em: 25/01/2010.

DURIGAN, M. E. Florística, dinâmica e análise proteica de uma Floresta Ombrófila Mista em São João do Triunfo, PR. 125 f. Dissertação (Mestrado em Manejo Florestal) - Setor de Ciências Agrárias, Universidade Federal do Paraná, Curitiba, 1999.

FIGUEIREDO FILHO, A.; SERPE, E. L.; PLODOWSKI, G.; SANTOS, D. F.; STEPKA, T. F.; BECKER, M. Crescimento sazonal em diâmetro de 16 espécies de uma Floresta Ombrófila Mista na Floresta Nacional de Irati, Parana, Brazil. In: CONGRESSO LATINOAMERICANO IUFRO. BOSQUES: LA CRECIENTE IMPORTANCIA DE SUS FUNCIONES AMBIENTALES, SOCIALES Y ECONÓMICAS, 2., v. 1., 2006. La Serena, Chile. Anais... La Serena: IUFRO-INFOR, 2006.

FONSECA, R. C. B.; RODRIGUES, R. R. Análise estrutural e aspectos do mosaico sucessional de uma floresta semidecídua em Botucatu, SP. Scientia Forestalis, Piracicaba, n. 57, p. 27 - 43, 2000.

GANDOLFI, S.; LEITÃO FILHO, H.; BEZERRA, C. L. F. Levantamento florístico caráter sucessional das espécies arbustivo-arbóreas de uma floresta mesófila semidecídua no município de Guarulhos, SP. Revista Brasileira de Botânica, v. 55, n. 4, p. 753 - 767, 1995.

INSTITUTO BRASILEIRO DE GEOGRAFIA E ESTATÍSTICA (IBGE). Manual técnico da vegetação brasileira. (Manuais técnicos de geociências). Rio de Janeiro, 1992. n. 1. 92 p.

Mapa de biomas do Brasil e o mapa de vegetação do Brasil. Disponível em: $\langle$ http://www.ibge.gov.br/home/presidencia/noticias/noticia_visualiza.php?id_noticia=169>. Acesso em: $15 / 02 / 2010$.

ISERNHAGEN, I.; MENEZES SILVA, S.; RODRIGUES, W.; GALVÃO, F. Listagem de espécies arbustivo-arbóreas citadas nos trabalhos de fitossociologia florestal no Paraná, Brasil: uma contribuição aos programas de recuperação de áreas degradadas (RAD). In: A fitossociologia florestal no Paraná e os programas de recuperação de áreas degradadas: uma avaliação. São Paulo. Instituto de Pesquisa e Estudos Florestais (IPEF), 2001. 175 p.

JARENKOW, J. A. Composição florística e estrutura da mata com araucária na Estação Ecológica de Aracuri, Esmeralda, Rio Grande Sul. 133 f. Dissertação (Mestrado em Ecologia) - Universidade Federal do Rio Grande do Sul, Porto Alegre, 1997.

LAMPRECHT, H. Silvicultura nos trópicos: ecossistemas florestais e respectivas espécies arbóreas: possibilidades e métodos de aproveitamento sustentado. Eschborn: GTZ, 1990. 343 p.

MANTOVANI, M.; RUSCHEL, A. R.; PUCHALSKI, A.; SILVA, J. Z.; REIS, M. S.; NODARI, R. O.; Diversidade de espécies e estrutura sucessional de uma formação secundária da Floresta Ombrófila Densa. Scientia Forestalis, n. 67, p. 14 - 26, 2005.

MAZZA, C. A. S.; MAZZA, M. C. M.; SANTOS, J. E. SIG aplicado à caracterização ambiental de uma unidade de conservação Floresta Nacional de Irati, Paraná. In: SIMPÓSIO BRASILEIRO DE SENSORIAMENTO REMOTO, 12., 2005, Goiânia, Anais... Goiânia: INPE, 2005. p. 2251-2258. 
MOSCOVICH, F. A. Dinâmica de crescimento de uma Floresta Ombrófila Mista em Nova Prata, RS. 130 p. Tese (Doutorado em Ciências Florestais) - Universidade Federal de Santa Maria, Santa Maria, 2006.

OLIVEIRA, R. J.; MANTOVANI, W.; MELO, M. M. R. F. Estrutura do componente arbustivo-arbóreo da floresta atlântica de encosta, Peruíbe, SP. Acta Botânica Brasilica, v. 15, n. 3, p. 391 - 412, 2001.

PIZZATO, W. Avaliação biométrica da estrutura e da dinâmica de uma Floresta Ombrófila Mista em São João do Triunfo, PR: 1995 a 1998. 172 f. Dissertação (Mestrado em Engenharia Florestal) Universidade Federal do Paraná, Curitiba, 1999.

SANQUETTA, C. R.; PIZZATO, W.; PÉLLICO NETTO, S.; EISFELD, R. L.; FIGUEIREDO FILHO, A. dinâmica da estrutura horizontal de um fragmento de Floresta Ombrófila Mista no Centro-Sul do Paraná. Revista Ciências Exatas e Naturais, v. 3, n. 1, p. 44 - 57, 2001.

SCHAAF, L. B. Florística, estrutura e dinâmica no período 1979-2000 de uma Floresta Ombrófila Mista localizada no sul do Paraná. 131 f. Dissertação (Mestrado em Engenharia Florestal) Universidade Federal do Paraná, Curitiba, 2001.

SCHNEIDER, P. R. Manejo florestal: planejamento da produção florestal. Santa Maria: UFSM, 2002. $195 \mathrm{p}$.

SHIVER, B. D.; BORDERS, B. E. Sampling techniques for forest inventory. USA; Canada: John Wiley \& Sons, 1996. 356 p.

SILVA, A. J. C.; NOGUEIRA, A. C.; CAPANEZZI, A. A.; GALVÃO, F.; KOZERA, C.; KUNIYOSHI, Y. S. Banco de sementes em Floresta Ombrófila Mista Aluvial - municípios de Araucária e Balsa Nova. In: CONGRESSO DE ECOLOGIA DO BRASIL, 8. 2007, Caxambu, MG. Anais... Caxambu, 2007. p. 2.

SOUZA, V. C.; LORENZI, H. Botânica sistemática: guia ilustrado para identificação das famílias de angiospermas na flora brasileira, baseado em APG II. Nova Odessa: Instituto Plantarum, 2005. 639 p.

WATZLAWICK, L. F.; SANQUETTA, C. R.; VALÉRIO, A. F.; SILVESTRE, R. Caracterização da composição florística e estrutura de uma Floresta Ombrófila Mista no município de General Carneiro, PR. Ambiência, Guarapuava, PR, v. 1, n. 2, p. 229 - 237, 2005.

WILLIANS, E. Nature conservation. In: The countryside notebook. Oxford: Blackwell Publications, 2005. $384 \mathrm{p}$. 